\title{
Da economia política à política econômica: o novo-desenvolvimentismo e o governo Lula
}

\author{
LECIO MORAIS \\ ALFREDO SAAD-FILHO*
}

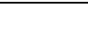

From political economy to economic policy: The neo-developmentalism and the Lula administration. This article critically reviews the design of neo-developmentalist economic policies in Brazil, in the first half of the last decade, and their relationship with the economic policies of the Lula administration after 2006. Paradoxically, the neo-developmentalist policies were implemented jointly with the main (neoliberal) macroeconomic policies which had been introduced earlier. The article reviews the relevant literature, and examines the contradictory nature of this 'inflection' of economic policy. So far, this combination of policies has achieved an unquestionable - though provisional - success, despite the persistence of the structural macroeconomic problems due to the continuity of the neoliberal policies.

Keywords: Brazilian macroeconomics; new developmentalism; Lula administration.

JEL Classification: B52; N16; O11; O54.
\end{abstract}

\section{INTRODUÇÃO}

No início do primeiro governo Lula, economistas de diversas orientações teóricas fora do mainstream foram surpreendidos por suas políticas macroeconômicas, que mantiveram inalteradas aquelas introduzidas pelo governo Fernando Henrique Cardoso (1995-2002) após a crise do real, em 1999. Essas políticas eram baseadas no paradigma neoliberal e, tipicamente, inspiradas pela abordagem dos mercados

\footnotetext{
* Câmara dos Deputados, Brasília. E-mail: lecio@uol.com.br. Departamento de Estudos do Desenvolvimento, SOAS, Universidade de Londres. E-mail: as59@soas.ac.uk. Agradecemos aos generosos comentários de Antonio Carlos Macedo e Silva e Luiz Carlos Bresser-Pereira. Os erros e omissões são de responsabilidade dos autores. Submetido: 21/12/2010; Aprovado: Fevereiro 12/2/2011.
} 
eficientes. Sua ênfase na "competitividade" e na estabilidade monetária substituiu gradualmente, a partir dos anos 1980, o paradigma desenvolvimentista periférico fundado no dirigismo estatal para assegurar o crescimento acelerado (Ferraz, Crocco e Elias, 2003, p. 14).

As políticas macroeconômicas mantidas por Lula eram fundadas no famoso tripé composto por uma política monetária determinada pelas metas de inflação, câmbio flutuante e uma política fiscal visando manter um superávit primário que compensasse o déficit nominal das contas públicas (no contexto deste artigo, essas são as "políticas neoliberais") ${ }^{1}$. Essas políticas são também associadas às reformas institucionais da década de 1990, que resultaram em forte liberalização comercial, desregulamentação financeira, uma crescente abertura da conta de capitais e outras reformas microeconômicas coerentes com o suposto da eficiência intrínseca dos mercados (denominadas aqui de "reformas neoliberais").

A perplexidade dos críticos era particularmente significativa porque críticas à continuidade das políticas neoliberais já eram feitas até mesmo por policymakers diretamente envolvidos na sua implementação. Por exemplo, já em 2001, Barros (2002, pp. 109-115) argumentava que o Plano Real (que sintetizou esse conjunto de políticas, a partir de 1994) tinha "envelhecido" e perdido "eficácia" por se manter prisioneiro de um falso "dilema fiscalismo versus desenvolvimentismo", e por não ter atentado para a estrutura produtiva interna, que vinha perdendo produtividade ante à concorrência da indústria internacional, graças à "opção liberal" do governo Fernando Henrique Cardoso.

Uma parte da bibliografia que critica esse continuísmo macroeconômico derivou de artigos acadêmicos e outra de livros destinados ao grande público. Seus autores tinham por orientação teórica o keynesianismo e o marxismo, em suas diversas versões. Podemos distinguir nessa produção crítica dois objetivos. O primeiro era demarcar os campos teóricos, por exemplo, quando os críticos se aplicavam em demonstrar a continuidade das políticas do governo anterior no governo Lula, explorando as contradições e limites dessa opção, e vaticinando seu "fracasso". A essa continuidade, esses autores antepunham um programa alternativo consagrado pelo pensamento de esquerda. Esse teria como inspiração histórica e analítica um arco abrangendo diferentes versões do nacional-desenvolvimentismo e do socialismo, incluindo a advogação de rupturas que permitiriam uma maior "liberdade" de ação da política econômica diante dos agentes privados. Essa produção acadêmica, representada, por exemplo, por Paula (2003a e 2005) e por trabalhos oriundos do Instituto de Economia da Unicamp ${ }^{2}$, entre muitos outros, se concentrou na análise do período 2003-2005.

\footnotetext{
${ }^{1}$ Essas políticas foram implantadas gradualmente no Brasil desde o início dos anos 1990, mas elas só passaram a ser exercidas integralmente a partir de 1999, após a crise cambial do real, nos moldes das acontecidas no México, em 1994, no Sudeste e Leste Asiático, em 1997, e na Rússia, em 1998. Após o colapso da política de "âncora cambial”, a moeda nacional foi sujeita a forte desvalorização, em janeiro daquele ano.

${ }^{2}$ Ver, por exemplo, sobre a política fiscal, até 2005, Lopreato (2007), sobre dinâmica do crescimento
} 
Um segundo objetivo dessa linha de análise heterodoxa era a formulação de propostas concretas de uma nova política macroeconômica e de políticas assessórias (de crédito, industrial etc.) ${ }^{3}$, formando um todo coerente e capaz de substituir as políticas neoliberais. As análises com esse objetivo acabaram fundando uma nova proposta de política econômica, denominada pelos seus autores como "novo-desenvolvimentismo" (ou "neodesenvolvimentismo") ${ }^{4}$. Essa proposta deveria funcionar como instrumento de intervenção no debate dentro e fora do governo Lula. Foi com base nelas que, a partir de 2006, o governo Lula passou a adotar novas iniciativas e políticas que se mesclaram às políticas macroeconômicas neoliberais, estabelecendo-se, dali em diante então, a política econômica híbrida que caracterizou esse governo até 2010, e que parece persistir no governo de sua sucessora.

\section{AS CRIITICAS À CONTINUIDADE DAS POLÍTICAS NEOLIBERAIS}

Em 2003, tendo em vista a evidente continuidade das políticas macroeconômicas, os seus críticos passaram a esgrimir contra o governo Lula os mesmos argumentos endereçados ao governo anterior. Esses críticos, muitos deles antigos apoiadores ou militantes do Partido dos Trabalhadores (PT) e de outras organizações de esquerda, vinham se sentindo crescentemente alienados com a guinada à direita do PT a partir de 1989, e sua acomodação ao jogo político institucional (ver Morais e Saad-Filho, 2005).

Essa postura crítica havia se intensificado durante o processo eleitoral, especialmente após a publicação da "Carta ao Povo Brasileiro" (Lula 2002) em junho de 2002, em meio a uma grave crise cambial e de refinanciamento da dívida federal desencadeada pelos mercados financeiros domésticos. A crise especulativa serviu para pressionar os principais candidatos a presidente da República a assumirem

econômico até 2006, Carneiro (2007), sobre a política econômica do governo Lula, até 2005, Carneiro (2006), e para uma análise política do governo Lula, até 2005, Boito Jr. (2006).

${ }^{3}$ Este artigo adota uma definição de política econômica incluindo a totalidade da capacidade do Estado de intervir institucionalmente e de forma sistemática no domínio econômico. Assim, a política econômica tem como núcleo as políticas macroeconômicas (formadoras dos "grandes preços": as taxas de câmbio, de juros, de inflação e de salário), mas englobando, também, outras ações institucionais como as políticas industrial, creditícia e de comércio exterior, e as políticas microeconômicas e de concorrência. Essa concepção abrangente de política econômica contraria a concepção usual, de origem neoclássica. Para uma definição semelhante, ver Carneiro (2006, p. 7).

${ }^{4} \mathrm{O}$ termo "novo-desenvolvimentismo", denominando um conjunto de políticas econômicas alternativas às políticas neoliberais (especialmente pós-Consenso de Washington), foi introduzido por Bresser-Pereira, que o utilizou no capítulo 20 de seu livro Desenvolvimento e crise no Brasil, em sua quinta edição revisada (Bresser-Pereira, 2003). Segundo esse autor, a denominação lhe foi sugerida por Yoshiaki Nakano em 2003 (Bresser-Pereira, 2006, p. 9), tendo por base argumentos desenvolvidos em Bresser-Pereira (2001). A denominação passou a ser mais difundida a partir de 2005, quando da publicação do livro Novo-Desenvolvimentismo, uma coletânea de artigos organizada por Sicsú, Paula e Michel (2005). Uma detalhada história intelectual do novo-desenvolvimentismo é apresentada em Bresser-Pereira (2011). 
um compromisso público de que, se eleitos, respeitariam os contratos vigentes em relação à dívida pública doméstica e externa, e apoiariam um programa de auxílio emergencial a ser prestado pelo Fundo Monetário Internacional (FMI), negociado pelo governo que findava. Esse programa concedia um grande empréstimo para evitar o estrangulamento cambial, e continha as habituais cláusulas restritivas às políticas monetária e fiscal a serem implementadas pelo futuro governo. Na sua "Carta", Lula comprometeu-se em implementar o programa do FMI e cumprir seus condicionantes 5 .

Essa produção crítica, geralmente ensaística, não raro significava um rompimento político-ideológico com o governo Lula por parte de acadêmicos ditos "heterodoxos". A sensação de estranhamento e perplexidade desses analistas com a continuidade das políticas neoliberais se agravava pelo fato de que economistas ligados à Fundação Getulio Vargas, do Rio de Janeiro - conhecido centro da academia conservadora - passaram a ocupar posições-chave no Ministério da Fazenda, enquanto o Banco Central continuava a ser dirigido por economistas ortodoxos e profissionais oriundos do mercado financeiro.

Por exemplo, Paula (2003b, pp. 8-9) e Paulani (2003, p. 25), partindo de pontos de vista teóricos distintos, fizeram uma crítica severa às políticas neoliberais, e atacaram a afirmação das autoridades econômicas do governo Lula de que só haveria uma "macroeconomia legítima e racional" (aquela praticada no governo FHC) por tentarem fugir ao debate sobre a teoria e a ideologia implícitas nessas políticas. Paulani (2003, p. 23) apontava também que uma política monetária que tem como único objetivo a meta de inflação e como único instrumento a regulagem da taxa básica de juros resultaria em sobrevalorização da moeda pela entrada de capitais de curto prazo, comprometendo os resultados da conta-corrente do balanço de pagamentos. Para Paulani (2003, p. 29), o erro dessa política de combate à inflação estava na presunção de que a alta dos preços se devia a uma inflação de demanda, enquanto sua aplicação deprimia o investimento e o crédito de forma permanente. Na mesma linha, Sicsú (2003) argumentou que, embora a taxa de juros seja eficaz em conter a inflação, o seu uso isolado pode ser contraproducente, porque pressões inflacionárias podem ser devidas também a deficiências de oferta ou choques externos, e, no Brasil, ao alto custo fiscal determinado pelo uso permanente de taxas de juro elevadas por razões de política econômica. Concordando com essas críticas, Cardim de Carvalho (2003, p. 77) aponta o risco de se manter a economia em recessão permanente, chamando a atenção de que, devido ao custo fiscal da política monetária, a política fiscal perdia seu papel anticíclico.

Por fim, Cardim de Carvalho (2003, p. 27), analisando os acordos do Brasil com o FMI, argumentou que as políticas neoliberais continuadas por Lula limitavam o poder discricionário das políticas macroeconômicas. Ele também indicou que não se pode atribuir ao FMI a autoria das políticas neoliberais, já que o gover-

\footnotetext{
${ }^{5}$ Outros três candidatos proeminentes também firmaram compromisso público semelhante em apoio ao programa do FMI.
} 
no Lula, assim como o seu antecessor, "[apropriava-se] das políticas do Fundo como suas".

Portanto, independente da orientação teórica desses economistas heterodoxos, havia um razoável consenso sobre as insuficiências das políticas neoliberais, bem como sobre as suas consequências macroeconômicas adversas, o que era evidenciado pelas baixas taxas de crescimento do PIB nos dois mandatos de FHC, e pela contínua vulnerabilidade das contas externas. Por fim, os economistas heterodoxos insistiam que as políticas neoliberais eram incompatíveis com políticas industriais e de transferência de renda promovendo a retomada do crescimento econômico e a redução da desigualdade de renda e riqueza.

Apesar dessa convergência, não havia unanimidade nessa literatura quanto às causas da continuidade das políticas macroeconômicas. A divisão principal se dava entre aqueles que consideravam essa continuidade como produto da fraqueza ideológica do governo Lula, que tinha escolhido trocar de valores ao chegar ao poder (Cardim de Carvalho, 2003; Paulani, 2003), e aqueles que defendiam ser tal continuidade fruto de uma situação contingente de correlação de forças políticas, que impunha o abandono das propostas petistas de administração do Estado professadas antes das eleições (Barbosa e Souza, 2010; Morais e Saad-Filho, 2005; Novelli, 2010; Sallum Jr. e Kugelmas, 2004).

A divergência entre essas posições tinha por clivagem a caracterização do período de crise cambial, desvalorização do real e virtual suspensão do refinanciamento da dívida mobiliária federal nos seis meses que antecederam às eleições de outubro de 2002: especificamente, se essa contingência teria força suficiente para tornar a adoção das políticas neoliberais uma imposição decorrente de um realismo político indeclinável ou, pelo contrário, se se tratava de um ato de vontade deliberadamente velado pela suposta ameaça de crise. Paulani (2003) alega que a crise não chegou a ameaçar a economia de um colapso; isso só ocorreria caso fosse iminente um default na dívida externa e um descontrole inflacionário. Entretanto, segundo ela, as reservas internacionais mantiveram-se estáveis até o final de 2002, em torno de US\$ 36 bilhões, apesar da fuga de capitais, não indicando, assim, a iminência de um colapso cambial. Nem tampouco ocorreu o propalado choque inflacionário em decorrência da desvalorização do real. Apesar da taxa de câmbio ter ido de $\mathrm{R} \$ 2$ por dólar, em junho, para $\mathrm{R} \$ 4$, em setembro, quando ocorreu o aceite da carta de intenções com o FMI, a pressão inflacionária se dissipou já no início de 2003.

Em contraste, Morais e Saad-Filho (2005) argumentaram que a crise de 2002 assumiu tal gravidade que - no âmbito da institucionalidade vigente - ela tendia a levar o país a um colapso cambial e monetário. O refinanciamento da dívida pública foi virtualmente paralisado a partir de maio, e a sua consequente monetização pressionou o mercado de dólares, levando a uma rápida desvalorização do real. Só em setembro - depois de firmado o acordo do FMI — o valor da moeda nacional começou a se recuperar. Essa crise, devida à desconfiança dos capitais financeiros no candidato à frente nas pesquisas eleitorais, poderia levar ao colapso cambial e da dívida pública, evento inaceitável para qualquer força política sem 
objetivo revolucionário e que disputasse o pleito com reais chances de vitória, como era o caso do PT e de seus principais aliados. A natureza inevitavelmente ensaística desse debate, carregado de subjetividade e dependendo estreitamente de argumentos contrafactuais dificulta, uma convergência sobre o tema; assim, seu mérito e suas conclusões permanecem em aberto.

Apesar de suas opiniões divergentes sobre a natureza da crise e as opções disponíveis ao primeiro governo Lula, esses dois grupos duvidavam - em graus variados - da capacidade do governo assegurar a retomada do crescimento econômico e de vir a ser politicamente bem-sucedido. Nesse contexto, há também análises mais matizadas, como a abordagem política de Boito Jr. (2006). Partindo de um estudo da composição de classes dos governos FHC e Lula, Boito Jr. (2006, p. 74) conclui que não se pode considerar o segundo apenas como uma "continuidade pura e simples" do seu antecessor, entendendo que Lula "amplia e dá uma nova dimensão" à estabilidade da política burguesa iniciada por FHC, embora estabelecendo uma relação diferente com as diversas frações do capital brasileiro e internacional. Esse autor não descartava, no entanto, a ocorrência de um processo de desenvolvimento sob um modelo "liberal-desenvolvimentista", em que pese a sua "dinâmica moderada e instável".

\section{O NOVO-DESENVOLVIMENTISMO COMO PROPOSTA DE POLÍTICA ECONÔMICA}

As principais sínteses teóricas sobre o novo-desenvolvimentismo, de inspiração keynesiana e estruturalista, encontram-se na introdução do livro homônimo, de 2005 (Sicsú, Paula e Michel, 2005), e em Bresser-Pereira (2006, 2011).

Para os primeiros, o novo-desenvolvimentismo oferece uma alternativa às políticas neoliberais e ao "velho desenvolvimentismo" (ou "nacional-desenvolvimentismo"), definido como uma industrialização dirigida pelo modelo de substituição de importações, que tinha como base a proteção do mercado interno e grande intervenção estatal no setor de infraestrutura e na produção de insumos básicos. Em outro paper, Sicsú, Paula e Michel (2007) desenvolvem uma crítica mais detalhada ao "velho desenvolvimentismo". Eles afirmam que, no caso brasileiro, a substituição de importações falhou por não ter sido acompanhada de absorção tecnológica e por ter incutido no empresariado doméstico uma mentalidade protecionista, devido ao fato do protecionismo tarifário ter sido generalizado e temporalmente ilimitado (pp. 514-51). As questões da competitividade internacional e da equidade interna ganham força nessa análise da experiência histórica, que se considera parcialmente malsucedida devido à inexistência de uma associação entre o protecionismo e uma efetiva incorporação do progresso técnico. Em linha com Fajnzylber (1989) e Cepal (1990), aqueles autores apontam essa baixa incorporação do progresso técnico como característica comum aos processos de industrialização na América Latina, determinando uma reduzida elevação da produtividade e um crescimento sem equidade social. Essa falta de 
incorporação do progresso técnico é a principal causa do comportamento espasmódico do crescimento e da competitividade em toda a região. Uma abordagem mais detalhada da questão, acompanhada por reflexões aprofundadas acerca da "doença holandesa", é oferecida por Bresser-Pereira (para uma revisão de suas contribuições nessa área, ver Bresser-Pereira, 2011).

Para aqueles autores, o novo-desenvolvimentismo tem duas fontes teóricas distintas. A primeira vem de Keynes e de economistas contemporâneos como P. Davidson e J. Stiglitz, e ela inspira o conceito de complementaridade entre Estado e mercado. A segunda fonte é o neoestruturalismo cepalino, interpretado por Fernando Fajnzylber, Luiz Carlos Bresser-Pereira e Yoshiaki Nakano. Daqui vem a ênfase na competitividade internacional através da incorporação de progresso técnico, e a necessidade da equidade social para o desenvolvimento bem-sucedido (Sicsú, Paula e Michel, 2005, p. xxxiv) ${ }^{6}$. Segundo esses autores, o novo-desenvolvimentismo pode ser sintetizado em quatro teses: “(1) não há mercado forte sem Estado forte; (2) não haverá crescimento sustentado [...] sem o fortalecimento ... do Estado e do mercado e sem implementação de políticas macroeconômicas adequadas; (3) mercado e Estados fortes somente serão construídos por um projeto nacional de desenvolvimento que compatibilize crescimento ... com equidade social; e (4) não é possível [reduzir] a desigualdade sem crescimento econômico a taxas elevadas e continuadas" (Sicsú, Paula e Michel, 2005, p. xxxv).

Segundo esses autores, o "Estado forte" é aquele capaz de regular os mercados, e eles rejeitam o axioma neoliberal de que a racionalidade individual nos mercados produz sempre o melhor resultado para a sociedade. Reciprocamente, um "mercado forte" é aquele capaz de abrigar empresas grandes e pequenas, que mantenha aberto o acesso à concorrência, e que assegure a equidade de oportunidades aos produtores e consumidores, condição essa que não pode ser garantida endogenamente pelo próprio mercado, mas apenas pela regulação estatal.

As políticas econômicas decorrentes da perspectiva novo-desenvolvimentista não se satisfariam, portanto, apenas com a "estabilidade monetária", objetivo maior das políticas neoliberais. Ao invés disso, seu objetivo é a "estabilidade macroeconômica". Este é um conceito mais abrangente de redução de incertezas relativas à demanda futura, criando um ambiente estável para a tomada de decisões de investimento privado. Isso inclui tanto a regulação estatal das taxas de juros, do câmbio e dos salários, quanto a redução da vulnerabilidade externa para defender a economia de choques externos e da volatilidade dos fluxos de capitais estrangei-

\footnotetext{
${ }^{6} \mathrm{O}$ pensamento considerado neoestruturalista pelos autores se refere ao sucessor da escola cepalina que associa o desenvolvimento econômico à equidade social, a partir de F. Fajnzylber (1989) e Cepal (1990); ver também Rodrigues (2006, p. 343 passim). Para Fajnzylber, a promoção da equidade não se deve à necessidade econômica de facilitar a realização do capital, mas sim à necessidade política de formar uma "nova aliança” para fortalecer e democratizar o Estado nacional na América Latina. Para uma explanação sobre uma nova política econômica antecedente ao novo-desenvolvimentismo, ver Bresser-Pereira e Nakano (2002 e 2003); e sobre a macroeconomia que sustenta essa política econômica e sua metodologia ver Bresser-Pereira (2005 e 2009) e Furquim e Gala (2004).
} 
ros mediante uma taxa cambial administrada e a imposição de controles de capitais, caso necessário ("blindagem da conta de capital") (sobre câmbio e fluxos de capitais, ver Sicsú, 2006). Esses objetivos só podem ser alcançados por políticas com objetivos múltiplos e pela complementaridade entre as políticas monetária, fiscal, cambial e salarial para influenciar os "grandes preços" da economia: as taxas de juros, de câmbio, de salário e de inflação (Bresser-Pereira, 2003, p. 281). As novas políticas macroeconômicas restabeleceriam a condição soberana da ação do Estado de controlar sua moeda e sua política fiscal, permitindo a adoção de uma política industrial de defesa da competitividade e da equidade (2005, pp. xl-xlviii).

Uma novidade significativa dessa formulação de política econômica por autores keynesianos brasileiros é o destaque atribuído à dimensão política do processo de desenvolvimento, incluindo como condição necessária a existência de um projeto nacional, "que expresse o sentimento de nação". Essa dimensão política se baseia na experiência histórica dos países hoje desenvolvidos e de seus sucessores leste-asiáticos, tendo como diretiva que a ligação entre os mercados nacionais e os internacionais deve trazer ganhos substanciais em termos de divisas, conhecimentos, empregos e bem-estar para o país. Para os autores, a globalização "é um projeto de desintegração nacional e enfraquecimento intelectual, econômico e cultural de todos os segmentos de uma sociedade”. Sem superar esse déficit do Estado-nação, mediante a adoção de um projeto nacional, mesmo as políticas econômicas alternativas fracassarão (2005, pp. xlviii-1). ${ }^{7}$

Bresser-Pereira (2006) oferece outra síntese do novo-desenvolvimentismo, que é apresentado como um "terceiro discurso": uma estratégia nacional de desenvolvimento alternativa ao "populismo" latino-americano e à ortodoxia convencional, representada pelas análises, diagnósticos, reformas e políticas do Consenso de Washington. Essa nova estratégia seria também "uma retomada da ideia de nação no Brasil e nos demais países da América Latina”. Isso reafirma a importância da dimensão política do Estado-nação para o novo-desenvolvimentismo, ao mesmo tempo em que se delineia a América Latina como área geopolítica de sua aplicação, seguindo a referência tradicional do pensamento estruturalista-cepalino?.

Ao diferenciar entre o "velho" e o novo desenvolvimentismo, Bresser-Pereira repete o argumento da competitividade visto acima, mas desloca seu enfoque para

\footnotetext{
${ }^{7}$ Esse argumento tem uma relação direta com as teses sobre a inadequação das políticas econômicas sugeridas pelos países capitalistas centrais (e pelas instituições multilaterais por eles controladas) para as economias periféricas, elaboradas por Amsden (2001, 2007) e Chang (2002).

${ }^{8} \mathrm{O}$ terceiro discurso se opõe ao "primeiro discurso ortodoxo convencional" (do Consenso de Washington), "da direita neoliberal e cosmopolita", e ao "segundo discurso da esquerda burocrático-populista” (Bresser-Pereira, 2006, p. 13).

${ }^{9} \mathrm{O}$ recorte regional para a América Latina decorre da concepção cepalina de que essa região, devido ao seu processo histórico comum de formação econômica e de criação de seus Estados nacionais, possui uma singularidade própria, de natureza estrutural, caracterizada pelo desenvolvimento dependente.
} 
a necessidade de adoção do modelo exportador seguido pelos países do Leste Asiático. Desse modo, o novo-desenvolvimentismo rejeita o protecionismo perene e o crescimento via demanda oriunda de um déficit público crônico. Para o autor, tais características do "velho" desenvolvimentismo não teriam sido defendidas por seus formuladores, Presbisch, Furtado e Inácio Rangel, mas por seus epígonos. Já a "ortodoxia convencional" é definida como uma representação da "hegemonia ideológica dos Estados Unidos sobre o resto do mundo [...] na verdade, o braço e a fala do neo-imperialismo" (2006, p. 17).

$\mathrm{O}$ autor resume assim as diferenças entre a "ortodoxia convencional" e o novo-desenvolvimentismo quanto ao "tripé do desenvolvimento" (2006: 19):

\begin{tabular}{|l|l|}
\hline $\begin{array}{l}\text { "Ortodoxia convencional": } \\
\text { forças do mercado, desde que: }\end{array}$ & $\begin{array}{l}\text { "Novo-desenvolvimentismo": } \\
\text { Um país se desenvolverá aproveitando as } \\
\text { forças do mercado, desde que: }\end{array}$ \\
\hline $\begin{array}{l}\text { (1) mantenha a inflação e as contas públicas } \\
\text { sob controle; }\end{array}$ & (1) mantenha a "estabilidade macroeconômica";* \\
\hline $\begin{array}{l}\text { (2) faça reformas microeconômicas orienta- } \\
\text { das para o mercado; }\end{array}$ & $\begin{array}{l}\text { (2) conte com instituições gerais que fortale- } \\
\text { çam o Estado e o mercado e com um conjunto } \\
\text { de políticas econômicas que constituam uma } \\
\text { estratégia nacional de desenvolvimento; }\end{array}$ \\
\hline $\begin{array}{l}\text { (3) obtenha poupança externa para } \\
\text { financiar seu desenvolvimento, dada a falta } \\
\text { de poupança interna. }\end{array}$ & $\begin{array}{l}\text { (3) seja capaz de promover a poupança interna, } \\
\text { o investimento e a inovação empresarial. }\end{array}$ \\
\hline
\end{tabular}

* Ver o conceito de "estabilidade macroeconômica", mais acima.

A dependência da poupança externa (déficit em transações correntes) deve ser evitada, e os ingressos de divisas decorrentes de investimento estrangeiro direto devem se destinar a atender à demanda cambial do investimento nacional no exterior ou para o aumento de reservas (ver também Bresser-Pereira, 2007, 2011). Para alcançar seus três objetivos, o novo-desenvolvimentismo deve (a) controlar as despesas e os déficits do governo, logrando uma poupança pública para financiar o investimento estatal; (b) dotar o Banco Central de um duplo mandato, adicionando ao controle da inflação o equilíbrio do balanço de pagamentos, e empregando, para tanto, dois instrumentos, a taxa de juros e a taxa cambial; e (c) administrar a taxa de câmbio de modo a dar competitividade às exportações e controlar as importações; os controles de capitais serão impostos quando necessário.

O grande ausente na literatura novo-desenvolvimentista é a ênfase na ampliação do mercado interno, um dos mais destacados pilares do estruturalismo cepalino. Essa ausência é contraposta pelo realce dado ao comércio externo e à competitividade internacional. Essa abordagem aproxima o novo-desenvolvimentismo do pensamento neoestruturalista presente na literatura da Cepal nos anos 1990, sendo justificada pela emergência de uma nova revolução tecnológica e da globalização (cf. Rodriguez, 2006, p. 377 passim). 


\section{O NOVO-DESENVOLVIMENTISMO COMO POLÍTICA ECONÔMICA APLICADA}

A partir de 2006 e, especialmente, durante o segundo governo Lula (20072010), a política econômica brasileira sofreu uma inflexão, e os resultados macroeconômicos foram positivos em termos do crescimento do PIB, fortalecimento de grandes empresas nacionais (estatais e privadas), distribuição de renda e redução da pobreza. A mais completa avaliação desse período, ainda muito recente, é oferecida por Barbosa e Souza (2010), sendo especialmente significativa por ser Barbosa um dos principais policymakers nesse período, enquanto secretário de política econômica do Ministério da Fazenda.

Várias inovações introduzidas por essa inflexão de política econômica foram defendidas pelo novo-desenvolvimentismo, e há uma clara correlação entre as políticas introduzidas, a forma como elas foram justificadas pelo governo, e aquela formulação teórica. No entanto, destaque-se que Barbosa e Souza não aludem ao novo-desenvolvimentismo como fonte dessas mudanças na política econômica. Ao contrapor as diferentes visões de política econômica - antes e depois da inflexão de 2006 - os autores referem-se a elas como "neoliberal" e "desenvolvimentista". Porém, as óbvias similitudes tornam inescapável o paralelo entre a última e as propostas novo-desenvolvimentistas delineadas acima.

Ao ser transformada em política econômica, uma proposta teórica sofre inevitavelmente uma série de modificações e adaptações próprias das restrições e constrangimentos da ação política. Além disso, como veremos abaixo, as propostas novo-desenvolvimentistas foram institucionalizadas apenas parcialmente, assumindo um caráter complementar, visto que as políticas macroeconômicas (monetária, cambial e fiscal) neoliberais mantiveram-se praticamente intactas durante todo o período.

Segundo Barbosa e Souza, a "aceleração do desenvolvimento econômico e social" foi alcançada "com manutenção da estabilidade macroeconômica", isto é, com controle da inflação, redução do endividamento líquido do setor público e diminuição da vulnerabilidade das contas externas diante de choques internacionais. O objetivo dos autores "é apresentar um resumo da política econômica que possibilitou tal desempenho".

A primeira observação a ser feita é sobre o conceito de "estabilidade macroeconômica", que é utilizado de forma mais restrita do que em Bresser-Pereira (2006). Não se adota como parte necessária da "estabilidade macroeconômica" uma política fiscal visando à formação de uma poupança pública (meta de déficit nominal zero), como também dela não faz parte uma política cambial visando a uma taxa de câmbio competitiva. Em segundo lugar, e de forma semelhante, a vulnerabilidade externa também é entendida de forma restrita, como o montante da dívida externa líquida. Com esse entendimento, o autor constata uma redução extraordinária na vulnerabilidade externa, que fez o país assumir uma inédita posição credora líquida a partir de 2007 , devido à redução da dívida externa bruta e à acumulação de reservas internacionais. Essa posição credora alcançou 
3,9\% do PIB em 2009, recuando um pouco para 2,7\% em 2010 (ver Barbosa e Souza, 2010, e a Tabela 2 abaixo).

Os autores explicam que, apesar de um forte ajuste macroeconômico (de inspiração ortodoxa) em 2003-2005, a taxa de crescimento do PIB não se acelerou significativamente, conforme seria esperado. Um novo período de elevação da taxa básica de juros entre setembro de 2004 e meados de 2005 — justificado pela "visão predominante da equipe econômica da época" - frustrou o crescimento em 2005, apesar da duplicação das exportações e de uma expansão creditícia apoiada por reformas microeconômicas, especialmente as mudanças na lei de falência e a criação do crédito consignado às rendas de salário e de aposentadorias da previdência social pública.

O desempenho macroeconômico insatisfatório (e, presume-se, a bateria de críticas de antigos aliados) gerou um debate no interior do governo Lula, ao final de 2005, entre a "visão neoliberal" e a "visão desenvolvimentista". Esse debate teria levado à inflexão da política econômica quando a equipe econômica inicial foi substituída por defensores de uma política de maior ativismo do Estado. Apesar de não compartilharem um pensamento homogêneo, estes adotaram uma "postura mais pragmática" com base em três linhas: [1] "adoção de medidas temporárias de estímulo fiscal e monetário para acelerar o crescimento e elevar o potencial produtivo da economia; [2] a aceleração do desenvolvimento social por intermédio do aumento nas transferências de renda e elevação do salário mínimo; e [3] o aumento no investimento público e a recuperação do papel do Estado no planejamento de longo prazo" (Barbosa e Souza, 2010, pp. 69-70).

Ao contrário da "visão neoliberal", que subestimava o potencial de crescimento da economia, os desenvolvimentistas argumentavam que havia potencial não utilizado devido aos ganhos de produtividade "ainda não aproveitados" decorrentes de ganhos de escala, à elevação do emprego nos setores formais, deslocando os trabalhadores de menor produtividade, à indução do investimento privado, e à abertura de novos mercados externos. Entretanto, esses ganhos só poderiam ser realizados se a taxa de crescimento fosse elevada pelo ativismo estatal fiscal e creditício, iniciando um círculo virtuoso que poderia elevar o crescimento anual do PIB "um ou dois pontos percentuais acima do estimado pelos adeptos da visão neoliberal".

O ativismo estatal deveria se voltar para "a redução da desigualdade da distribuição de renda e para o aumento do investimento público". O primeiro objetivo foi concretizado através da expansão da Bolsa Família - um programa focalizado de garantia de renda mínima para famílias mais pobres - e da elevação real do salário mínimo, o que proporcionou também um aumento substancial das transferências para os aposentados e pensionistas da previdência social pública ${ }^{10}$. $\mathrm{O}$ segundo objetivo levou a um grande programa de investimento plurianual ${ }^{11}$, sobretudo em energia e transporte, que articulou o investimento público com o investi-

\footnotetext{
${ }^{10}$ Desde a promulgação da Constituição de 1988, os benefícios da previdência pública e o seguro-desemprego não podem ser inferiores ao salário mínimo legal.

${ }^{11}$ Denominado, adequadamente, de Programa de Aceleração do Crescimento (PAC).
} 
mento das empresas estatais e privadas especialmente através de concessões em infraestrutura, e uma forte expansão do crédito para investimento, principalmente pelo setor bancário público. Segundo os "desenvolvimentistas", esse programa recuperaria uma infraestrutura econômica defasada por 30 anos de baixo investimento, ao mesmo tempo em que incluiria desonerações fiscais "para incentivar o investimento privado e o mercado de massa" (2010, p. 73). Outro aspecto emblemático da mudança de concepção do gasto público é que esse aumento no investimento estatal poderia ser financiado tanto por receitas tributárias quanto por novo endividamento, fato inédito desde as reformas orçamentárias de 1986, e violando um "tabu" da política fiscal".

A forte resposta da economia a esse ativismo estatal, devida, em parte, a um ambiente internacional de liquidez e à expansão da demanda interna e externa até meados de 2008, fez com que a receita tributária e o PIB crescessem de modo a reduzir a dívida pública, medida em proporção do PIB (ver Tabela 1). Assim, melhoraram os indicadores fiscais, apesar da constante valorização do real perante o dólar ${ }^{13}$. Durante a fase mais aguda da atual crise internacional, houve um maior afrouxamento fiscal e expansão da liquidez, o que minimizou o impacto doméstico do choque contracionista. A economia se recuperou fortemente já em 2010, apesar da deterioração da conta de transações correntes, resultando em um ambiente interno de grande otimismo.

Tabela 1: Dívida Pública Interna (\% PIB)

\begin{tabular}{|l|c|c|c|c|c|c|c|c|c|c|}
\hline & 2001 & 2002 & 2003 & 2004 & 2005 & 2006 & 2007 & 2008 & 2009 & 2010 \\
\hline $\begin{array}{l}\text { Dívida líquida do setor } \\
\text { público }\end{array}$ & 53.3 & 55.5 & 58.7 & 51.7 & 51.5 & 44.0 & 41.0 & 38.4 & 42.8 & 40.4 \\
\hline $\begin{array}{l}\text { Dívida líquida do gov. } \\
\text { federal (inclusive BC } \\
\text { e res. internacionais) }\end{array}$ & 32.7 & 35.3 & 37.2 & 32.5 & 34.1 & 30.8 & 30.3 & 24.0 & 29.3 & 27.4 \\
\hline $\begin{array}{l}\text { Dívida mobiliária } \\
\text { federal interna bruta }\end{array}$ & 37.8 & 33.6 & 43.7 & 41.5 & 48.9 & 44.8 & 44.5 & 41.1 & 43.4 & 43.4 \\
\hline $\begin{array}{l}\text { Resultado nominal } \\
\text { do governo central } \\
\text { (+ = déficit) }\end{array}$ & 2.1 & 0.7 & 4.1 & 1.5 & 3.8 & 3.2 & 2.3 & 0.8 & 3.4 & 1.3 \\
\hline $\begin{array}{l}\text { Resultado primário } \\
\text { do governo central } \\
++=\text { déficit) }\end{array}$ & -1.9 & -2.4 & -2.6 & -3.0 & -2.9 & -2.2 & -2.3 & -2.4 & -1.3 & -2.2 \\
\hline
\end{tabular}

Fonte: Banco Central do Brasil; até 2009, Boletim mensal, diversos números; para 2010: Notas à Imprensa, jan. 2011.

\footnotetext{
${ }^{12}$ A dívida mobiliária interna federal no Brasil sempre foi instrumento exclusivo de política monetária e cambial. Seu crescimento, desde a década de 1970, se deu em virtude dos custos dessas políticas e pela assunção de seus próprios encargos e de outros custos financeiros como os decorrentes da manutenção (e, mais recentemente, da ampliação) das reservas internacionais do Banco Central do Brasil (ver Morais, 2010).

${ }^{13}$ A taxa de cambio nominal dólar/real cresceu de 0,3460 ao final de 2003, para 0,5988 em 2010, valorizando-se o real em $73 \%$ em sete anos.
} 
O relevante a destacar é que essas medidas de política econômica foram introduzidas de forma complementar às políticas macroeconômicas vigentes, e não em sua substituição. Por exemplo, a política fiscal manteve a meta de resultado primário, mas, por norma legal, esse passou a ser entendido como resultado primário em despesas correntes, portanto excluindo os investimentos públicos e as contas de algumas grandes empresas estatais ${ }^{14}$. Isso resultou em uma disponibilidade maior de recursos para investimentos no setor público. Entretanto, ainda persiste um déficit nominal apesar do resultado primário favorável e do crescimento econômico (ver Tabela 1) ${ }^{15}$. Quanto à inflação, quando ocorreram choques adversos na oferta de alimentos non-tradables e subiram os preços internacionais das commodities, em 2007-2008, o governo respondeu com desonerações tributárias, minimizando tais choques e associando medidas fiscais às medidas monetárias no controle da inflação, seguindo a concepção novo-desenvolvimentista do uso de vários instrumentos complementares de política econômica. Da mesma forma, a política econômica associou desonerações fiscais com a ampliação do crédito para elevar o investimento privado de forma seletiva, medidas que são geralmente consideradas pela "visão neoliberal" como redutoras da eficiência da alocação de recursos, sendo tendencialmente desestabilizadoras e, portanto, contraproducentes. Ao mesmo tempo, o governo vem elevando significativamente o custo do trabalho desde 2004, mediante um forte crescimento real do salário mínimo, inclusive em 2008 e 2009 , durante o choque mais imediato da crise internacional.

\section{AVALIAÇÃO DAS ALTERAÇÕES DE POLÍTICA E A INFLUÊNCIA DO NOVO-DESENVOLVIMENTISMO}

A construção teórica de uma nova política econômica no Brasil, desenvolvendo a teoria contemporânea e reelaborando a experiência do nacional-desenvolvimentismo, teve por impulso a superação de aspectos importantes do neoliberalismo,

\footnotetext{
${ }^{14}$ Ao contrário da metodologia-padrão utilizada para apuração da necessidade de financiamento do governo, no Brasil as contas de ativos e passivos financeiros das empresas estatais também eram incluídas, mesmo aquelas que não dependiam de nenhum recurso fiscal para operar. Com isso, a realização de investimento autofinanciados, ao transformar de ativos financeiros em ativo imobilizado, implicava déficit na NFSP. O principal efeito dessa inclusão para as empresas estatais era a restrição sobre o seu volume de investimento produtivo em setores estratégicos como petróleo e geração de energia elétrica, tradicionalmente não dependentes de recursos fiscais. Com essa alteração da definição do resultado primário, a Petrobras - principal petroleira do país - foi retirada da necessidade de financiamento a partir de 2008, e a Eletrobrás — bolding das maiores empresas geradora de energia elétrica — deixou de constar a partir de 2010; outras estatais, no entanto, ainda permanecem no cálculo.

${ }^{15}$ Segundo Barbosa e Souza (2010), uma meta que eventualmente zerasse o déficit nominal corrente "deveria ficar para um segundo momento, quando o Brasil atingisse uma taxa real de juros mais baixa". Desse modo, a concepção de resultado primário como meta da política fiscal se mantém coerente com a "visão neoliberal", mas é de certo modo invertida, mediante seu adiamento para um futuro em que essa redução se viabilize mediante também a diminuição do custo da dívida (e não apenas pela elevação do superávit primário).
} 
incluindo as políticas macroeconômicas e as reformas microeconômicas. As políticas neoliberais vêm sendo crescentemente vistas como nocivas em um contexto periférico, especialmente após as crises cambiais que atingiram o Sudeste Asiático. Essas se deveram, em grande medida, à desregulamentação financeira e ao livre movimento de capitais, que geraram instabilidade cambial, movimentos especulativos e o crash. A continuidade dessas políticas nos primeiros anos do governo Lula, tido como portador de mudanças políticas e socioeconômicas, originou críticas e catalisou a elaboração de propostas alternativas de política econômica.

Enquanto alternativa mais difundida, e conforme examinado acima, o novo-desenvolvimentismo contém um corpo articulado de políticas econômicas baseadas teoricamente no keynesianismo e no estruturalismo cepalino. Seu objetivo é representar uma nova estratégia de desenvolvimento, superando o nacional-desenvolvimentismo tradicional e adequando os seus princípios às novas realidades emergentes da revolução tecnológica e da globalização. Essa política econômica advoga a necessidade de uma ruptura com as políticas macroeconômicas neoliberais, a serem substituídas por novas políticas monetárias, cambiais e fiscais, e subordina a adoção das novas políticas à existência de um projeto nacional para o Estado brasileiro. A defesa da ruptura tem como fundamento a ideia de que as políticas macroeconômicas neoliberais são incompatíveis com a soberania do Estado para implementar uma política econômica atendendo ao objetivo nacional de retomada do desenvolvimento com estabilidade macroeconômica e com um menor custo fiscal.

A base teórica do novo desenvolvimentismo guarda semelhança com o neoestruturalismo de Fajnzylber (1989) e Cepal (1990), que entende a equidade como objetivo inerente e necessário ao desenvolvimento dos países latino-americanos. Para Fajnzylber (1989), por exemplo, a equidade não visa facilitar a realização do capital, mas sim fundamentar a formação de uma "Nova Aliança" política nacional incorporando os socialmente excluídos. Entretanto, como vimos acima, assim como no neoestruturalismo cepalino está ausente do novo-desenvolvimentismo uma ênfase explícita no fortalecimento do mercado interno, ponto característico do nacional-desenvolvimentismo estruturalista.

Muitas das medidas de política econômica preconizadas pelo novo-desenvolvimentismo passaram a ser adotadas pelo governo Lula a partir de 2006, mas sem ter havido uma ruptura com as políticas macroeconômicas neoliberais. Essas mudanças - consideradas, corretamente, por Barbosa e Souza (2010) como uma inflexão e não como uma "nova política" - se deram de forma complementar (ou mesmo aditiva) às políticas macroeconômicas neoliberais, que foram mantidas praticamente sem alterações, apesar de tensões durante o período 2006-2010.

O sentido mais amplo das mudanças foi dar ativismo ao Estado no domínio econômico, principalmente (a) no fomento à produção via financiamento de capital e investimentos públicos em infraestrutura; (b) na expansão do mercado de consumo de massa via programas de transferência de renda, elevação do salário mínimo e do crédito ao consumo; e (c) apoio à formação de grandes empresas brasileiras, transformando-as em agentes competitivos em frente às multinacionais tanto no mercado interno como no mercado internacional, via crédito e outros incentivos regulatórios para aquisições e fusões, e também via apoio diplomático, em especial nas relações Sul-Sul. 
Algumas das mudanças da política econômica não se apresentam explicitamente no programa novo-desenvolvimentista, apesar de serem coerentes com ele, como é o caso da estratégia de formar "empresas campeãs", que tem inspiração na experiência de países emergentes do Leste Asiático, além de medidas associadas com a expansão do mercado de consumo. Quanto a esse último aspecto, nota-se que o novo-desenvolvimentismo destaca genericamente a "equidade", enquanto o discurso do governo Lula enfatizava a "inclusão".

Esse caráter complementar, ou adicional, da inflexão de política econômica no segundo governo Lula não permite considerá-la como uma política novo-desenvolvimentista inteiramente coerente. Apesar dos bons resultados atingidos em termos de crescimento econômico e distribuição de renda, e da melhora do posicionamento do Brasil no sistema capitalista internacional, a inflexão ocorrida a partir de 2006 definiu uma política que pode ser denominada mais apropriadamente como "híbrida", associando políticas macroeconômicas visando à estabilidade monetária e presumindo, implicitamente, o equilíbrio espontâneo dos mercados, com políticas objetivando à aceleração do desenvolvimento e a equidade social mediante um destacado ativismo estatal.

Diferentemente do que seria de prever, essa convivência de políticas econômicas supostamente antagônicas vem obtendo resultados tão favoráveis quanto inesperados, apesar da continuidade de problemas decorrentes da manutenção das políticas macroeconômicas neoliberais. Houve uma generalizada melhora das variáveis econômicas a partir de 2006, algumas delas apontando, inclusive, para mudanças estruturais em curso na economia brasileira. No setor externo, por exemplo, nota-se (a) a elevação constante e acelerada, em valores absolutos, dos ativos brasileiros no exterior, em especial dos investimentos diretos e dos créditos comerciais, mostrando que o país passou a financiar parte considerável de suas exportações (para os dados a seguir, ver Tabela 2); e (b) a estabilidade do passivo externo líquido total como porcentagem do PIB, apesar da crise internacional deflagrada em setembro de 2008 .

Apesar disso, também se nota que outros dois indicadores externos importantes não sugerem alterações estruturais, já que podem sofrer reversão a depender de circunstâncias conjunturais. Esses incluem (a) o crescimento das reservas internacionais, que é compensado por idêntico volume de passivos estrangeiros em portfólio, de grande liquidez; e (b) a posição credora externa, que depende da capacidade do sistema financeiro doméstico de manter elevada a oferta de crédito em reais. Internamente, é possível tomar como indicador de mudanças estruturais a redução monotônica da pobreza absoluta de 35,8\% das famílias, em 2003, para $21,4 \%$ em $2009^{16}$, e o forte aumento da oferta de crédito interno por bancos privados e estatais, que passou de $24,6 \%$ do PIB, em 2003 , para $46,6 \%$ do PIB em 2010 (o crédito dos bancos privados cresceu de $14,8 \%$ para $27,1 \%$ do PIB, enquanto o dos bancos estatais cresceu de $9,8 \%$ para $19,5 \%$ do PIB).

\footnotetext{
${ }^{16}$ Fonte: Pesquisa Nacional por Amostra de Domicílios, http://www.ibge.gov.br/home/estatistica/ populacao/trabalhoerendimento/pnad2004/default.shtm.
} 


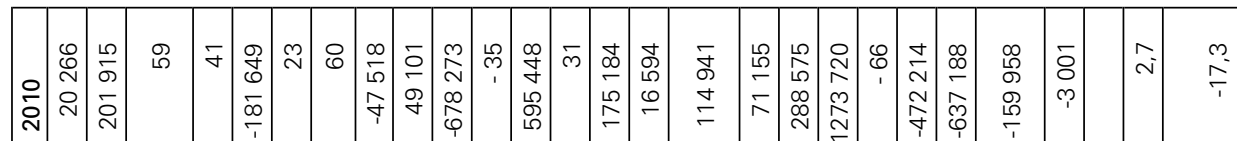

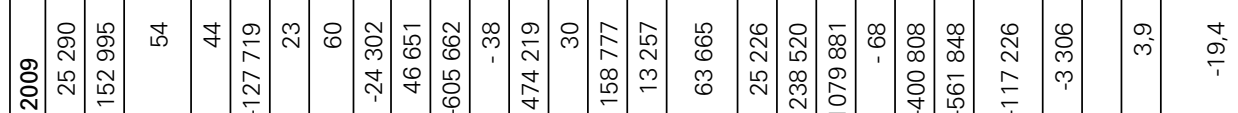

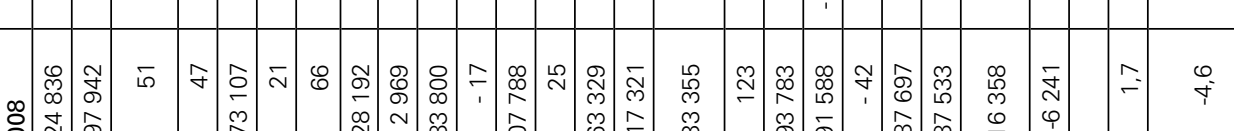

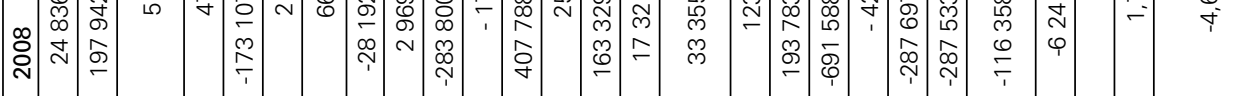

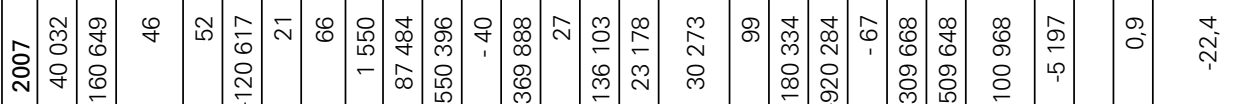

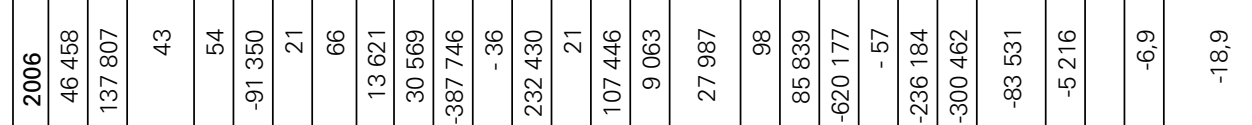

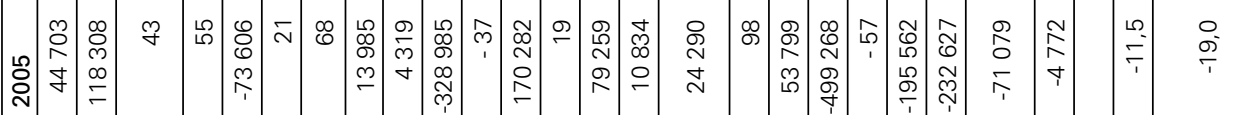

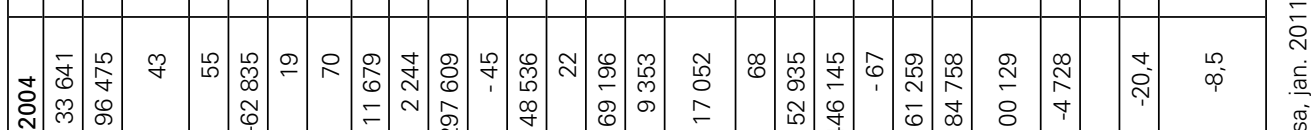
ì

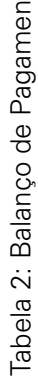

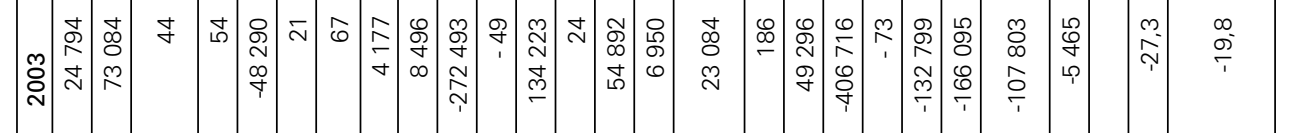

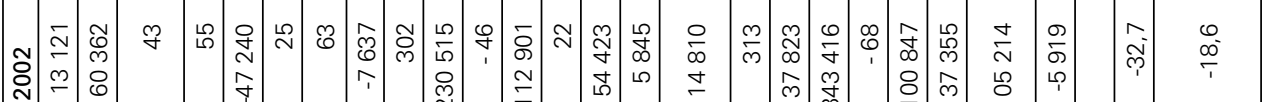

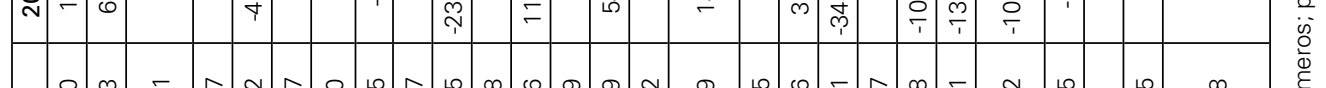

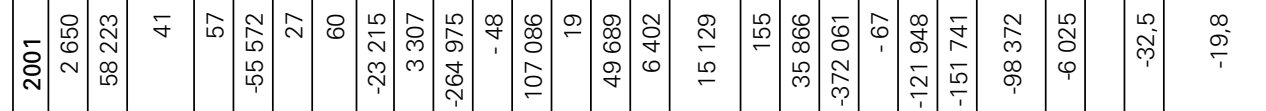

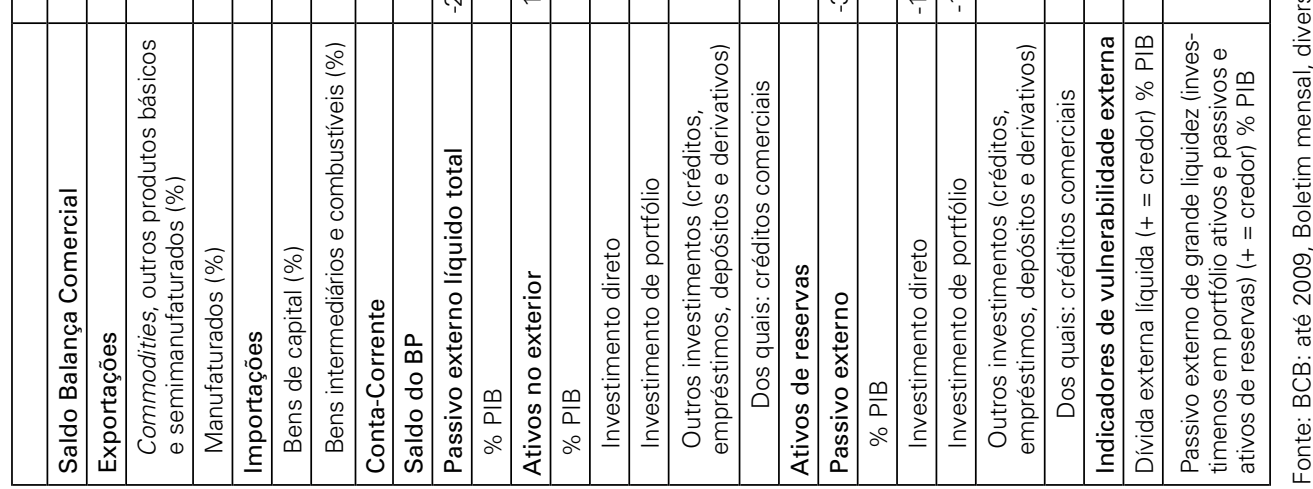


Por outro lado, persistem os problemas decorrentes da manutenção das políticas macroeconômicas neoliberais, inclusive em conformidade com as críticas anteriormente feitas pelos novo-desenvolvimentistas. Entre esses problemas, destacam-se (a) a sobrevalorização do real, que tem reduzido a competitividade internacional, levando à queda do saldo comercial e contribuindo para a deterioração da pauta de exportações, conforme sugerido pela composição commodities/manufaturados da balança comercial; além disso, o país tem tido um crescente déficit em transações correntes desde 2008; e (b) a pressão fiscal devida ao alto custo de uma política de meta inflacionária, simultaneamente com uma conta de capitais aberta. Essa pressão se revela no precário equilíbrio fiscal decorrente das tensões entre sustentar, ao mesmo tempo, crescentes reservas de divisas, as políticas monetárias e cambiais, e os programas de investimento público e de transferência de rendas.

Esta situação inusitada, em que uma "política híbrida" logrou atingir um sucesso amplo e significativo, foi certamente inesperada. A perplexidade generalizada devida ao bom desempenho da economia brasileira deve-se ao suposto de que tal mescla de políticas é insustentável, tanto pela perspectiva do mainstream quanto pela "heterodoxia" novo-desenvolvimentista. Esse resultante inesperado coloca-nos diante da necessidade de explicar por que a inflexão, que, desde 2006, "hibridizou" políticas macroeconômicas neoliberais com políticas contrastantes de desenvolvimento e equidade via ativismo estatal, alcançou resultados tão positivos.

Uma possível explicação seria que ocorreu uma suspensão momentânea dessa incompatibilidade devido a causas contingentes e exógenas à economia nacional especificamente, a excepcional liquidez internacional no período 2003-2008. Essas circunstâncias extraordinárias teriam permitido que as medidas heterodoxas fossem absorvidas momentaneamente pelos agentes internos e externos, bloqueando a crise de desconfiança que anteciparia o seu "inevitável" impacto adverso nas contas públicas e na inflação, através da suspensão dos investimentos e da fuga de capitais. Nesse caso, a incompatibilidade voltaria a se impor quando essa conjuntura for revertida, o que é inevitável dada à natureza cíclica da economia internacional.

Como mostram Barbosa e Souza (2010), essa explicação é insuficiente, pois a política híbrida continuou a dar bons resultados mesmo quando as circunstâncias internacionais favoráveis foram abruptamente substituídas por uma grave crise, em setembro de 2008. A reação do governo à nova situação aprofundou suas políticas de estímulo à renda e à demanda, acentuando o ativismo estatal. Supostamente, essa reação não só impediu que o choque externo inviabilizasse os ganhos atingidos com a "inflexão" (como a elevação dos investimentos públicos e privados, o aumento da renda e a queda da desigualdade), como permitiu a volta ao crescimento a partir do final de 2009, em que pese - outra vez - o retorno da sobrevalorização do real e a elevação do custo fiscal da política monetária e do regime de flutuação cambial.

Outra explicação - mais abrangente que a anterior - seria que, apesar da incompatibilidade em questão ser verdadeira, sua suspensão provisória deve-se a uma singular conjunção de fatores políticos e econômicos inscritos no desenvolvimento do capitalismo brasileiro. Em primeiro lugar, não se deve subestimar a capacidade de forças políticas "alternativas" operarem apesar da ideologia hegemô- 
nica, especialmente quando a força do consenso ortodoxo está em declínio, como demonstra Bresser-Pereira (2001) ${ }^{17}$. Essa capacidade do governo Lula de operar em oposição ao mainstream pode ter sido reforçada, a partir de 2005, pela evolução favorável da liquidez internacional e pela melhora rápida (e rara) nas condições econômicas de todas as classes sociais, em resposta às políticas do governo. Por sua vez, essa resposta rápida pode ser explicada pela existência de ganhos "potenciais de produtividade" na economia, até então não mobilizados, conforme argumentado por Barbosa e Souza (2010). Em segundo lugar, deve-se atentar para a presença singular de uma liderança política carismática e dotada de imaginação política, como Lula comprovou ao exercer o governo.

A singularidade e a complexidade da situação histórica nas quais se inserem a inflexão da política econômica também apontam para sua fragilidade. Primeiro, porque as consequências adversas das políticas neoliberais continuam a se agravar na mesma proporção em que elas obstaculizam uma maior liberdade de ação do Estado. A coexistência desses problemas com os sucessos alcançados até agora pela "inflexão" revelam a incongruência e a provisoriedade da situação atual. Segundo, a ausência da liderança carismática de Lula, a partir de 2011, e a possibilidade de o governo ter que impor perdas a alguns setores sociais devido à dinâmica cíclica de uma economia capitalista periférica podem desestabilizar a base de sustentação da administração da nova presidente Dilma Rousseff. Nesse caso, a incompatibilidade intrínseca da política econômica da "inflexão" voltaria a se manifestar.

Por fim, é importante considerar que a atual dinâmica global sugere que mudanças significativas estão em curso, e que podem beneficiar os chamados países emergentes periféricos. Em especial, o deslocamento do centro dinâmico do sistema capitalista para o Leste e o Sul Asiáticos pode significar uma situação estruturalmente mais favorável para o capitalismo brasileiro (e de outros "emergentes"), através de um longo período de afrouxamento da sua restrição de balanço de pagamentos. Esse efeito pode ser ainda mais acentuado, no caso brasileiro, pela descoberta recente de vastas reservas petrolíferas no litoral brasileiro, sob a plataforma continental. Isso pode ajudar a mascarar a incompatibilidade entre as políticas neoliberais e as novo-desenvolvimentistas ou, por outro lado, facilitar uma nova onda de mudanças das políticas macroeconômicas que tornem possível a ampliação dos ganhos obtidos no período 2006-2010.

\section{CONCLUSÃO}

Este artigo mostrou como a proposta de política econômica novo-desenvolvimentista, inspirada no keynesianismo e no neoestruturalismo cepalino dos anos 1990, buscou dar coerência a um conjunto de políticas macroeconômicas correspondendo

\footnotetext{
${ }^{17}$ Para uma abordagem mais detalhada do declínio do (Pós-) Consenso de Washington, ver Fine, Lapavitsas e Pincus (2001), Jomo e Fine (2006) e Saad-Filho e Johnston (2005).
} 
ao momento vivido pelo Brasil na primeira metade da última década. Essas novas políticas atribuem ao Estado um papel central. Seus objetivos derivam de um projeto político visando implementar uma estratégia nacional de desenvolvimento voltada para a superação do hiato econômico e social que separa o país dos estados do centro capitalista desenvolvido, o que não pode ser alcançado apenas por condições de mercado. As condições necessárias à implementação dessa proposta incluem a negação da primazia do mercado e a existência de um "Estado forte", entendido como aquele capaz de regular o mercado de modo a garantir uma estabilidade macroeconômica mais abrangente que a estabilidade monetária, e que, ao mesmo tempo, fortaleça esse mercado como principal produtor de riqueza. A construção desse Estado forte tem como precondição um desenvolvimento com equidade social.

A institucionalização parcial de várias propostas novo-desenvolvimentistas no segundo governo Lula se deu através da chamada "inflexão" da política econômica, que preservou o núcleo das políticas macroeconômicas introduzidas pelas reformas neoliberais do governo Fernando Henrique Cardoso, resultando em uma política econômica de natureza híbrida. Inesperadamente, em parte devido a condições externas favoráveis, e em parte aproveitando com imaginação política os "potenciais de ganhos de produtividade" da economia brasileira, essa política híbrida logrou um sucesso incontestável não só em termos de crescimento econômico, mas também através de uma melhoria da distribuição de renda e de uma redução da pobreza historicamente inédita. Ao mesmo tempo, a manutenção dos objetivos restritos das políticas neoliberais continuou a gerar graves problemas nas contas externas e fortes pressões fiscais, derivadas diretamente da sobrevalorização da moeda nacional e do elevado custo fiscal da política monetária e do livre movimento de capitais.

O resultado francamente favorável dessa política híbrida pôs à prova a suposta incompatibilidade entre o núcleo de políticas neoliberais com as medidas de caráter desenvolvimentista. Essa incompatibilidade, apontada tanto pelos novo-desenvolvimentistas como pelo mainstream no pensamento econômico, sugeria que a associação de políticas que têm por base, por um lado, a primazia do mercado e, por outro, o ativismo estatal, estaria fadada ao insucesso ab initio.

De forma sumária e exploratória, este artigo sugere que o inesperado sucesso dessa política híbrida não pode ser explicado apenas pelas condições extraordinárias de liquidez internacional, desde 2003, visto que a boa fase da economia brasileira não foi interrompida pela crise de 2008. Esse artigo indica que, apesar dos dois componentes da política atual do governo serem fundamentalmente incompatíveis, eles puderam operar em conjunto devido a uma complexa conjunção de fatores internos e externos. Além da já mencionada liquidez externa, os fatores mais relevantes foram a imaginação política da equipe econômica do governo Lula, que soube aproveitar as brechas surgidas na ortodoxia devido ao declínio do consenso neoliberal, e a rápida melhoria dos indicadores de emprego, renda e investimento devida às iniciativas desenvolvimentistas.

Entretanto, tudo indica que essa suspensão da incompatibilidade entre a política econômica e seu núcleo de políticas macroeconômicas é provisória. Os crescentes problemas do país na conta de transações correntes, e o ônus fiscal derivado das intervenções para moderar a sobrevalorização do real tendem a criar tensões 
insuportáveis com o ritmo de crescimento alcançado até 2010. Os ganhos obtidos com as novas políticas terão maior probabilidade de se consolidar caso os avanços institucionais e as políticas macroeconômicas apontadas pela própria literatura novo-desenvolvimentista sejam implementados com maior vigor durante o governo Dilma Rousseff. Isso poderá acontecer com menor dificuldade caso venha a se constituir, nos próprios termos do novo-desenvolvimentismo, um novo consenso de política econômica. Esse consenso envolveria uma repactuação do poder incluindo parte considerável das elites econômicas e das classes populares, em torno do objetivo de desenvolvimento com equidade social. O escopo para tal consenso depende não apenas de negociações internas. Ele depende também, de maneira crucial, da continuidade das mudanças estruturais na economia global beneficiando os novos países emergentes da periferia.

\section{REFERÊNCIAS BIBLIOGRÁFICAS}

AMSDEN, A. (2001) The Rise of 'the Rest': Challenges to the West from Late-Industrializing Economies. Oxford: Oxford University Press.

AMSDEN, A. (2007) Escape from Empire: the Developing World's Journey through Heaven and Hell. Cambridge, Mass: MIT Press.

BARBOSA, N. e SOUZA, J. A. P. (2010) 'A Inflexão do Governo Lula: Política Econômica, Crescimento e Distribuição de Renda’, in: E. Sader e M. A. Garcia (orgs.) Brasil: entre o Passado e o Futuro. São Paulo: Fundação Perseu Abramo e Editora Boitempo. Também disponível em: http://nodocuments.files.wordpress.com/2010/03/barbosa-nelson-souza-jose-antonio-pereira-de-a-inflexao-do-governo-lula-politica-economica-crescimento-e-distribuicao-de-renda.pdf. Acessado em: $12 / 2 / 2011$.

BARROS, L. C. Mendonça de (2001) 'Os Desafios da Macroeconomia Brasileira', in: R. Bielschowski e C. Mussi (orgs.) Políticas para a Retomada do Crescimento. Brasília: IPEA.

BOITO Jr., A. (2006) 'A Burguesia no Governo Lula', in: E. Basualdo e E. Arceo (orgs.) Neoliberalismo y Sectores Dominantes - Tendencias Globales y Experiencias Nacionales. Buenos Aires: CLACSO.

BRESSER-PEREIRA, L. C. (2005) 'Macroeconomia Pós-Plano Real: As Relações Básicas', in. Sicsú, L. F. de Paula e R. Michel (orgs.) Novo-Desenvolvimentismo: um Projeto Nacional de Crescimentos com Eqüidade Social, Barueri-SP: Manole, e Rio de Janeiro: Fundação Konrad Adenauer.

BRESSER-PEREIRA, L. C. (2001) 'Decisões Estratégicas e "Overlapping Consensus" na América Latina', Revista de Economia Política, 21 (4), pp. 3-29.

BRESSER-PEREIRA, L. C. (2003) Desenvolvimento e Crise no Brasil: História, Economia e Política de Getúlio Vargas a Lula; $5^{\text {a }}$ edição revisada. São Paulo: Editora 34.

BRESSER-PEREIRA, L. C. (2004) “Novo-Desenvolvimentismo”, Folha de S.Paulo, 19/9/2004.

BRESSER-PEREIRA, L. C. (2006) 'O Novo Desenvolvimentismo e a Ortodoxia Convencional', São Paulo em Perspectiva, 20 (3), pp.5-24.

BRESSER-PEREIRA, L. C. (2009) 'Os Dois Métodos e o Núcleo Duro da Teoria Econômica', Revista de Economia Política, 29 (2), pp.163-190.

BRESSER-PEREIRA, L. C. (2011) Crônica do Novo Desenvolvimentismo e Sua Macroeconomia Estruturalista, manuscrito.

BRESSER-PEREIRA, L. C. e GALA, P. (2007) 'Porque a Poupança Externa Não Promove Crescimento', Revista de Economia Politica, 29 (2), pp. 163-190.

BRESSER-PEREIRA, L. C. e NAKANO, Y. (2002) 'Uma Estratégia de Desenvolvimento com Estabilidade', Revista de Economia Política, 22 (3), pp. 146-177.

BRESSER-PEREIRA, L. C. e NAKANO, Y. (2003) 'Crescimento Econômico com Poupança Externa?’, Revista de Economia Politica, 23 (2), pp. 3-27.

CARDIM DE CARVALHO, F. (2003) 'A Influência do FMI na Escolha de Políticas Macroeconômicas 
em uma Economia Emergente: o Caso do Brasil', in: J. Sicsú, J. L. Oreiro e L. F. de Paula (orgs.) Agenda Brasil: Políticas Econômicas para o Crescimento e Estabilidade de Preços. Barueri-SP: Manole e Rio de Janeiro: Fundação Konrad Adenauer.

CARNEIRO, R. (2006) 'Introdução', in: A Supremacia dos Mercados e a Política do Governo Lula. São Paulo: Editora Unesp.

CARNEIRO, R. (2007) 'Dinâmica de Crescimento da Economia Brasileira: Uma Visão de Longo Prazo’. Texto para Discussão n 130, agosto 2007. Campinas-SP: IE/Unicamp. Disponível em: http:// www.eco.unicamp.br/Downloads/Publicacoes/TextosDiscussao/texto130.pdf.

CEPAL (1990) Transformación Productiva e Equidad. Santiago: Cepal.

CHANG, H.-J. (2002) Kicking Away the Ladder: Development Strategy in Historical Perspective. London: Anthem Press.

FAJNZYLBER, F. (1989) 'Industrialización en América Latina: de la "Caja Negra” al "Casillero Vacío”. Santiago: Cepal.

FERRAZ, J. C., CROCCO, M., e Elias, L. A. (2003) 'Apresentação', in: Liberalização Econômica e Desenvolvimento. São Paulo: Futura.

FINE, B., LAPAVITSAS, C. e PINCUS, J. (orgs.) (2001) Development Policy in the Twenty-first Century: Beyond the post-Washington Consensus. Londres: Routledge.

FURQUIM, L. e GALA, P. (2004) 'O Método Pragmático', in: Y. Nakano, J. M. Rego e L. Furquim (orgs.) Em Busca do Novo: O Brasil e o Desenvolvimento na Obra de Bresser-Pereira. Rio de Janeiro: Editora FGV.

JOMO K.S. e FINE, B. (orgs.) (2006) The New Development Economics after the Washington Consensus. Londres: Zed Books.

LOPREATO, F. L. C. (2007) A Política Fiscal Brasileira: Limites e Entraves ao Crescimento. Texto para Discussão n ${ }^{\circ} 131$, agosto 2007. Campinas-SP: IE/Unicamp. Disponível em: http://www.eco. unicamp.br/Downloads/Publicacoes/TextosDiscussao/texto131.pdf.

LULA da Silva, L. I. (2002) Carta ao Povo Brasileiro. São Paulo, 22/6/2002. Disponível em: http:// www2.fpa.org.br/portal/modules/news/article.php?storyid=2324. Acessado em: 26/12/2010.

MORAIS, L. (2010). 'Financiando o Desenvolvimento: Fontes para um Novo Projeto Nacional', in: Desenvolvimento: Ideias para um Projeto Nacional. São Paulo: Anita Garibaldi e Fundação Maurício Grabois.

MORAIS, L. e SAAD-FILHO, A. (2005) Lula and the Continuity of Neoliberalism in Brazil: Strategic Choice, Economic Imperative or Political Schizophrenia? Historical Materialism, 13 (1), pp. 3-31.

NOVELLI, M. N. (2010) 'A Questão da Continuidade da Política Macroeconômica entre o Governo Cardoso e Lula (1995-2006)', Revista de Sociologia e Política, 18 (36), http://www.scielo.br/pdf/ rsocp/v18n36/14.pdf. Acessado em 28/2/2011.

PAUlA J. A. de (org.) (2003a) A Economia Política da Mudança. Belo Horizonte: Autêntica.

PAUlA J. A. de (2003b) 'Apresentação', in: A Economia Política da Mudança. Belo Horizonte: Autêntica.

PAULANI, L. (2003) 'Brasil Delivery: Razões, Contradições e Limites da Política Econômica nos Primeiros Seis Meses do Governo Lula’, in: J. A. de Paula (org.) A Economia Política da Mudança. Belo Horizonte: Autêntica.

RODRIGUEZ, O. (2006) El Estructuralismo Latinoamericano. México: Cepal.

SAAD-FILHO, A. e JOHNSTON, D. (orgs.) (2005) Neoliberalism: A Critical Reader. Londres: Pluto Press.

SALLUM Jr., B. e KUGELMAS, E. (2004) 'Sobre o Modo Lula de Governar', in: B. Sallum Jr. (org.) Brasil e Argentina Hoje: Politica e Economia. Bauru-SP: USC.

SICSÚ, J. (2006) 'Rumos da Liberalização Financeira Brasileira', Revista de Economia Política, 26 (3), pp. 507-515.

SICSÚ, J., PAULA, L. F. de; e MICHEL, R. (2005) 'Introdução', in: Novo-Desenvolvimentismo: um Projeto Nacional de Crescimentos com Eqüidade Social. Barueri-SP: Manole e Rio de Janeiro: Fundação Konrad Adenauer.

SICSÚ, J., e OLIVEIRA, S. de C. (2003) 'Taxa de Juros e Controle de Inflação no Brasil', in: J. Sicsú, J. L. Oreiro e L. F. de Paula (orgs.). Agenda Brasil: Políticas Econômicas para o Crescimento e Estabilidade de Preços. Barueri-SP: Manole e Rio de Janeiro: Fundação Konrad Adenauer. 